\title{
The Blue Zones: areas of exceptional longevity around the world
}

\author{
Michel Poulain, Anne Herm and Gianni Pes*
}

\begin{abstract}
The aim of this study was to compare the level of population longevity and the characteristics of four geographic areas where unusually high proportions of longlived individuals have been observed. For these areas (Ogliastra in Sardinia, Okinawa in Japan, the Nicoya peninsula in Costa Rica and the island of Ikaria in Greece). The term of 'blue zone' (BZ) given to these areas is defined as a limited region where the population shares a common lifestyle and environment and whose exceptional longevity has been accurately verified. This paper discusses the use of different indexes to measure the longevity of a population. As a preliminary result of our investigations we confirm the exceptional level of male longevity in the Sardinian BZ and both male and female longevity in Okinawa. Considering possible explanations, we observed that $\mathrm{BZ}$ populations are geographically and/or historically isolated (islands and mountainous regions). These populations succeeded in maintaining a traditional lifestyle implying an intense physical activity that extends beyond the age of 80, a reduced level of stress and intensive family and community support for their oldest olds as well as the consumption of locally produced food. This is likely to have facilitated the accumulation of ideal conditions capable of limiting the factors that negatively impact on health in most Western populations. These people experienced the epidemiological transition - and its implications - in relative recent times, and their remarkably good health status during ageing could be the result of a delicate balance between the benefits of the traditional lifestyle and those of modernity (increased wealth, better medical care). All these factors could have promoted an ideal milieu for the emergence of long-lived phenotypes at the population level.
\end{abstract}

\footnotetext{
${ }^{*}$ Michel Poulain (correspondance author), Estonian Institute for Population Studies, Tallinn University, Estonia; IACCHOS, Université catholique de Louvain, Belgium.

Email: michel.poulain@uclouvain.be

Anne Herm, Estonian Institute for Population Studies, Tallinn University, Estonia.

Gianni Pes, Department of Clinical and Experimental Medicine, Università degli Studi di Sassari, Italy.
} 


\section{Individual longevity versus population longevity}

Longevity is a phenomenon related to individuals (individual longevity) as well as to populations as a whole (population longevity). While an exceptional age at death or the extreme survival of the oldest old individuals generally allows identifying the first phenomenon, the second can only be characterised through various indexes that are mostly associated with life tables computed for that population as a whole. When searching for the determinants of population longevity, the relevant characteristics or behaviours are those shared by a large part of the population. By considering these common characteristics, the chance to find more powerful explanatory variables is increased as most persons concerned are born and live in the same place and thus are more likely to share the same genetic make-up, early life conditions as well as traditional behaviours and habits, including the same locally produced food. So, by identifying areas where people live the longest, the search for longevity determinants could be improved.

Practically speaking, gerontologists use the term longevity to refer to any individual who is beyond the age 90 and actively functional. Living to 100 is an attractive threshold in the lifespan for the media as well as for research although it does not have any demographic significance in itself. Other age thresholds could be used to define the gates of longevity ${ }^{1}$ but the majority of research dealing with longevity considers usually centenarians. Based on the proportion of centenarians enumerated in censuses or mortality rates, the first potential longevity areas were identified at the beginning of the 20th century. The US Census Bureau compared the proportion of centenarians in different countries and pointed out the exceptional cases of Bolivia with 75 centenarians per 100,000 in 1900, Bulgaria with 60 in 1905 and the Philippines with 51 in 1903 (Bowerman 1939).

In the January 1973 issue of National Geographic magazine, the physician Alexander Leaf gave a detailed account of his journeys to countries of purported long-living people: the Hunzas from Pakistan, the Abkhazians from the Soviet Union, and Ecuadorians from Vilcabamba. According to Leaf, there were ten times more centenarians in these countries than in most Western countries and he pointed out that each of them was characterised by poor sanitation, infectious diseases, high infant mortality, illiteracy, and a lack of modern medical care making the inhabitants' extreme longevity even more extraordinary (Leaf 1973). However, some years later Mazess and Forman showed that age exaggeration was predominant in Vilcabamba with a large number of the men and women who tended to increase their age in order to improve their social status or to promote local tourism (Mazess and Forman 1979). Later Leaf acknowledged this conclusion and made a final statement agreeing

1 As an example, in Okinawa, every year on the third Monday of September, during the 'Respect for the Aged Day', those persons who reached the age of 97 are celebrated by the local municipality following a special ritual called 'Kajimaya' symbolising one's return to youth (The Secret of Longevity the Okinawan Way! (http://www.dietriffic.com/2009/02/06/longevity/) 
that no evidence proves the unusual ages in the village of Vilcabamba (Leaf 1981). More recently, demographers have become increasingly concerned with the accuracy of longevity claims given the unprecedented rise in very old people in developed countries (Jeune and Vaupel 1999; Young et al. 2010). As a consequence, more careful checks have been conducted resulting in a systematic invalidation of all allegedly long-living populations on earth as most claims of extreme age appeared to be undocumented or exaggerated. In 1999, following the publication of data showing extreme male longevity in Sardinia (Deiana et al. 1999), this scepticism pushed demographers to assess the validity of the alleged ages of the oldest olds in Sardinia (Koenig 2001). Based on a strict validation method, the ages of Sardinian centenarians were thoroughly proven to be correct (Poulain et al. 2006). This validation was based on investigations in the civil register of births from the two last decades of the XIX century and the register of deaths from the last two decades of the XX century. Considering the marginal annotation on death found in the birth register, all centenarians were identified by place of birth. Surprisingly, the spatial distribution of Sardinian centenarians according to their place of birth was far from random. Figure 1 helps to clarify the difference in the spatial distribution of centenarians in terms of low or high prevalence, as well as presence or absence of concentration of centenarians.

The number of centenarians born in a given place was reported to the number of newborns in the same place a century earlier. The spatial distribution of centenarians by place of birth smoothed by a Gaussian method was fully different from the original one that considered the distribution of centenarians by place of residence without considering the variation in the size of the population (Figures 1a and 1b).

As a result of the validation process, an area has been identified in the mountainous part of Sardinia with a significantly higher proportion of centenarians out of population born in the same place. This area was called the "blue zone'2 (Poulain et al. 2004) and the concept of longevity blue zones has since been elaborated as areas where the population is characterised by a significantly higher level of longevity compared with neighbouring regions, provided that the exceptional longevity of people in this population has been fully validated. In practice, a blue zone (BZ) is defined as a rather limited and homogenous geographical area where the population shares the same lifestyle and environment and its longevity has been proved to be exceptionally high. Other validated BZs have been found so far in Okinawa (Japan), on the Nicoya peninsula (Costa Rica) and on the island of Ikaria (Greece).

The advantages of the BZ concept are evident as potential longevity determinants may be found among common traits of the concerned population and characteristics of the shared lifestyle and environment. Moreover some of longevity determinants, identified for one BZ, could apply to populations of other BZs as well. Accordingly,

2 The term was chosen simply because at the time the authors used a blue pen on a map to mark the villages with long-lived population. 
Figures 1a, b, c and d:

Spatial distribution of long-lived subjects in a given area

(a) Low density

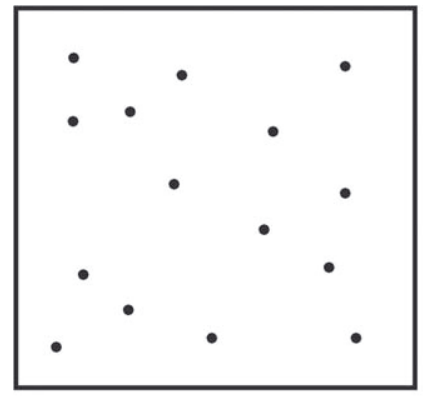

(c) Spatially randomly distributed (no concentration)

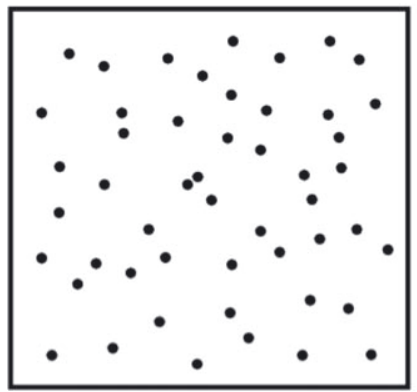

(b) High density

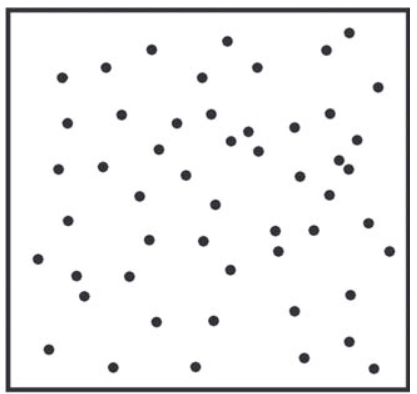

(d) Non randomly distributed (concentration)

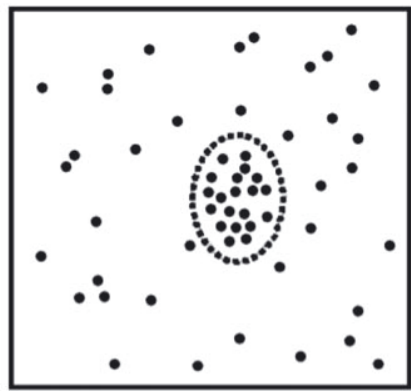

developing research investigations on several BZ populations and comparing their characteristics and behaviour is a potential step forwards when searching for longevity determinants. In this perspective, the present contribution proposes a first comparison of the longevity level as observed in the four BZs identified so far.

\section{Data and method}

To identify a BZ and to prove the exceptional longevity of its population it is necessary first to validate the individual longevity of people living in this area and more precisely to assess the exact age at death or the extreme survival of oldest olds in the concerned population. Age misreporting and, more specifically, age exaggeration must be ruled out. Perls explained that "there are several geographical areas that have claimed inhabitants with extreme longevity", and would be therefore considered as longevity areas, "but after closer examination these claims have been found to be false" (Perls et al. 2002). He concluded that such cases of extreme longevity 
Figures 2a and 2b:

Spatial distribution of centenarians in Sardinia

(a) Crude distribution by place of residence

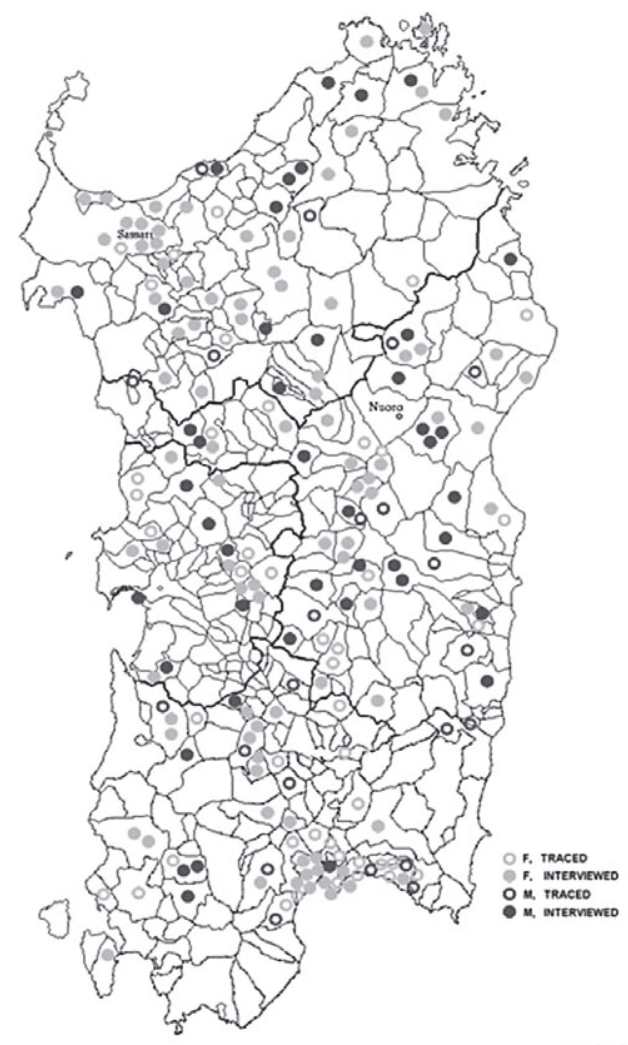

(b) Smoothed distribution by place of birth after adjusting for birth cohort size.

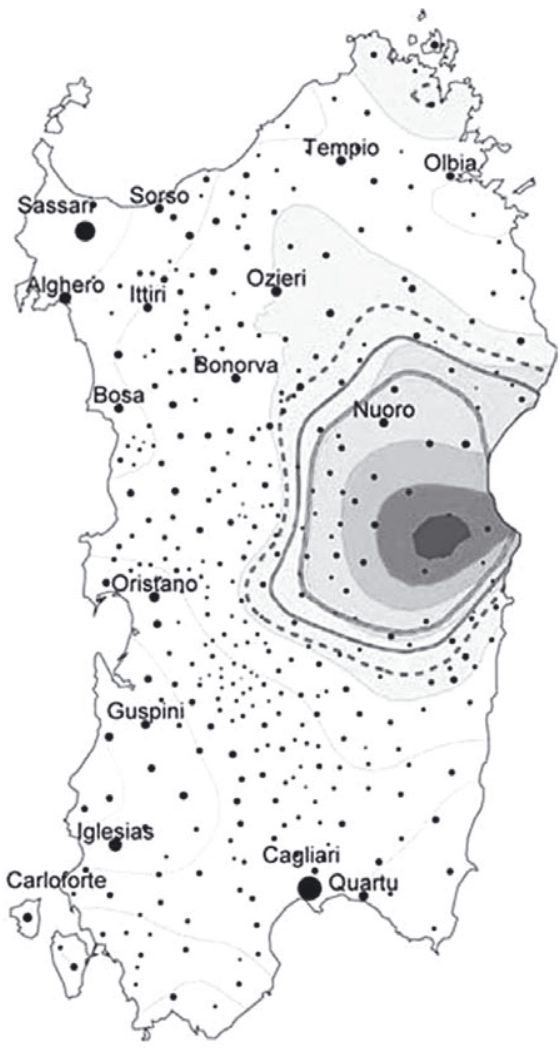

required detailed scrutiny because they are so incredibly rare. Young et al. (2010) listed various cases of invalidation of extreme ages while Poulain (2010) applied validation rules on a selection of supposedly long-living persons. In addition to the validation rules for individual centenarians, the validation of an extreme population longevity demands several specific investigation steps that could vary depending on the current availability of data sources for every specific population. In order to assess the level of population longevity that is estimated through the average individual longevity within a given population, data on all births and deaths occurring within this population must be collected. The key objective is to ensure exhaustive data on births a century ago, data on currently surviving centenarians and data on deaths of centenarians during the last decades. 
More precisely, the methodology used for identifying the first BZ in central Sardinia was the following one:

- a target area was selected covering all municipalities located in the Nuoro and Sassari provinces-two areas that emerged as potential places for exceptional longevity according to AKEA research results (Deiana et al. 1999);

- birth registers of municipalities in this area from 1880 to 1901 were scrutinised and the numbers of births were counted;

- based on marginal annotations of the date of death on the birth record, persons who died at age 100 and over were exhaustively identified;

- additional centenarians still alive were identified, whether they were surviving at their place of birth or elsewhere; ${ }^{3}$

- the age of each centenarian was validated according to accepted criteria for individual age validation;

- an Extreme Longevity Index (ELI) was computed as the ratio between the number of centenarians born between 1880 and 1901 and the total number of births recorded during the same time interval. This index, expressed as the number of centenarians per 10,000 newborns, is equivalent to the probability for any person born in that municipality to reach 100 years of age, there or anywhere else;

- thereafter a Gaussian spatial smoothing method was used to outline the area where ELI reached the maximum value.

The extreme longevity area identified in Sardinia and named as Blue Zone (BZ) includes a group of 14 villages in Barbagia and Ogliastra, covering the highest mountain area of Sardinia. ${ }^{4}$ The total population of this BZ is currently about 40,000 inhabitants who are mainly engaged in pastoral and agricultural activities and follow a relatively traditional lifestyle.

During the period 1880-1900, covered by the centenarians validation project (AKEA II) 17,965 people were born within the BZ area, 91 persons (47 men and 44 women) among whom reached the age of 100 . The resulting ELI values per 100,000 births are 512 and 506, for men and women respectively. For the rest of Sardinia, ELI values are significantly lower, with 103 for men and 264 for women (Poulain et al. 2004).

Starting from 2005, in cooperation with D. Buettner, a journalist writing for National Geographic, the BZ concept was extended to other relevant regions of the earth (Buettner 2012). Exceptional longevity at population level has been identified and validated so far in three other settings: the island of Okinawa in Japan, the peninsula of Nicoya in Costa Rica and the island of Ikaria in Greece (Figures 3). Compared to the situation in the first BZ in Sardinia, we faced more difficulties to

\footnotetext{
3 The survival of centenarians born in the municipality and surviving outside was checked by contacting the family or the administration of the current municipality of residence.

4 The highest mountain of Sardinia is Punta La Marmora, $1856 \mathrm{~m}$ above sea level.
} 
validate the population longevity in these three BZs because of limited availability of appropriate data sources. Indeed the situation is quite different between the three settings.

In Okinawa, as elsewhere in Japan, the individual validation of age is based on the koseki, a family register containing records of all members of a family, including gender, dates and places of birth, names of parents, dates of marriage and divorce if any, date and place of death (Saito 2010). Unfortunately, for privacy reasons, data extracted from the koseki such as birth and death records are only accessible by directly asking the relatives of the concerned persons or for official legal proceedings (Willcox et al. 2008). Accordingly, individual age validation can only be performed by a direct interview of centenarians alive and comparing self-reported information during the interview with data found on their personal koseki documents. In 2005 Willcox et al. (2008) recruited 52 centenarians alive in Okinawa and reached the conclusion that 49 of them were actually older than 100 years of age while the other three were 2, 3 and 6 years younger than alleged. Censuses, statistics on age at death and regional life tables are available for Okinawa ensuring an exhaustive coverage of centenarians. Still, one must keep in mind that age in these data is often based on koseki records. Various additional investigations developed by Willcox et al. (2008) on aggregate statistics confirmed the overall reliability of the data. Even if some doubt still exists on the large number of centenarians found in Okinawa as demonstrated by the first author (Poulain 2011), the exceptional longevity in Okinawa could not be put into question and Okinawa should be considered as a BZ.

In the Nicoya Peninsula, the identification and validation of age of the oldest olds and the assessment of the population longevity were performed based on public voting lists (padrón electoral) disseminated by the Supreme Electoral Tribunal (Tribunal Supremo de Elecciones) and produced from the birth registry. The later includes data on births, naturalisations and deaths of all ever-living Costa Ricans who contacted the civil registration system since its computerisation in 1970 (RoseroBixby 2008). Each of them was given a unique identification number, either at birth or at naturalisation, appearing on their identification card or cédula. The age of the oldest olds appearing on their cédula was successfully confronted with self-reported information given during the interview. The data quality and the higher level of longevity in Nicoya in comparison to the rest of Costa Rica are confirmed by the results presented by Rosero-Bixby in this yearbook (2013). These support the BZ status of the Nicoya Peninsula.

In Ikaria, census data and age-at-death statistics obtained from Statistics Greece were considered and confronted with individual data extracted from the dimotologio, an administrative registry that includes demographic information on all Greek citizens of a given municipality. Unfortunately, for the oldest olds on the island no birth records could be found and therefore the extinct-cohort method based on an exhaustive identification of those surviving above 90 as well as of persons being part of the same birth cohorts who died during the two last decades was used to estimate the level of population longevity. Individual age validation was successfully achieved during an exhaustive base of interviews with all those aged 90 and above in 
the northern part of the island by using a battery of questions on the occurrence of demographic events and the age of close relatives (Poulain and Pes 2009).

\section{First attempt to compare the BZs}

Conventionally, the apparent exceptional longevity of a population is inferred from the existence of an unusually large proportion of centenarians/nonagenarians. The centenarian prevalence $(\mathrm{CP})$, i.e. the ratio between the number of living centenarians in a given population and the total resident population, is largely used in the literature as well by the media. However, the reliability of this indicator for measuring and comparing longevity between different populations deserves critical evaluation as it is sensitive to a number of biases owing to migration and changes in fertility. For example, in case of a population that experienced large-scale immigration flows in the younger generations or a baby boom the $\mathrm{CP}$ will fail to identify remarkable survival of persons in old ages as the proportion of elders is artificially lowered. On the contrary, where the younger population has decreased due to emigration the proportion of elderly may result artificially increased. In such cases the prevalence or proportion of oldest olds is no longer reliable to measure longevity and to compare it between populations. Nevertheless, $\mathrm{CP}$ is still the most frequently used indicator by gerontologists as well as by national and regional authorities eager to claim a longevity status for the area of the concerned population.

Compared to CP, life tables provide a better measurement of longevity and allow comparing different populations more safely. The cohort life table is computed from mortality rates of a given birth cohort observed during one century or longer while the period life table is calculated on a fictive cohort by considering mortality rates for each age group at a given time. In most populations longevity is rising so fast that only the same cohorts of different populations should be compared and accordingly cohort life tables are preferred. Nevertheless computing a cohort life table is not a straightforward exercise as different methodologies and assumptions should be used while ad-hoc data are not always available. As a result, very few countries produce cohort life tables and no cohort life table exist up to now for any of the BZs.

A closely related indicator, the Centenarian Rate (CR), has been proposed by demographers to compare longevity levels. It has been introduced by Robine and Caselli (2005) as the ratio of the number of persons aged 100 years who were forty years earlier 60 years old in the same population or, more precisely, living within the same territory. This index is easy to calculate by using census data and is said to "eliminate the impact of the size of the cohort, the role of migration, naturalization, fertility and infant mortality" (Robine and Caselli 2005). However, there may still be 
Figures 3:

Geographical location of the Ogliastra, Ikaria, Costa Rica and Okinawa BZs
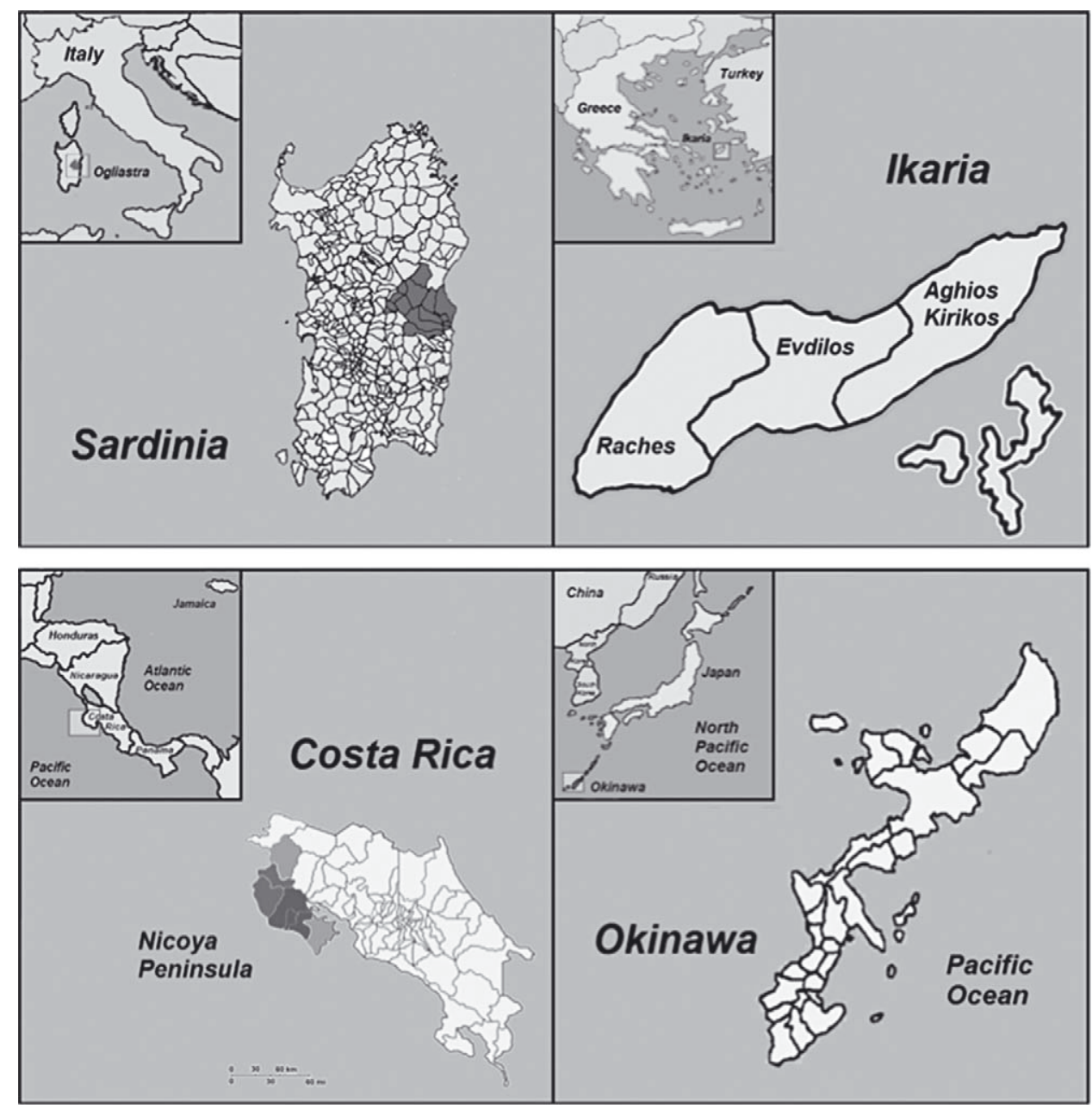

some bias when migration flows between age 60 and 100 are not negligible. ${ }^{5}$ The $\mathrm{CR}$, as it was initially proposed, measures the average longevity of the members of a specific cohort by counting how many individuals who were 60 years old in the census forty years before the time of measurement and later reached age

5 This is a situation existing in some areas regarded as highly favourable for retirement, such as Florida in the US. In countries where retirement age coincides with a higher level of migration, it may be better to compare the survival between 75 and 100 . 
Table 1:

Centenarian Rate (CR) for the 1900 birth cohort (number of persons surviving to 100 years for 10,000 persons alive at 60 years)

\begin{tabular}{|c|c|c|c|c|c|c|}
\hline Country & $\begin{array}{c}\text { Females aged } \\
60 \text { in } 1960\end{array}$ & $\begin{array}{c}\text { Females aged } \\
100 \text { in } 2000\end{array}$ & $\begin{array}{c}\text { Female } \\
\text { CR }\end{array}$ & $\begin{array}{l}\text { Males aged } \\
60 \text { in } 1960\end{array}$ & $\begin{array}{l}\text { Males aged } \\
100 \text { in } 2000\end{array}$ & $\begin{array}{c}\text { Male } \\
\text { CR }\end{array}$ \\
\hline Italy & 248571 & 1941 & 78.1 & 212849 & 412 & 19.4 \\
\hline of which Sardinia & 5889 & 64 & 108.7 & 5594 & 25 & 44.7 \\
\hline Japan & 310764 & 3948 & 127.1 & 305703 & 900 & 29.5 \\
\hline of which Okinawa & 2925 & 145 & 495.7 & 2069 & 17 & 82.2 \\
\hline France & 270842 & 2965 & 109.5 & 239348 & 450 & 18.8 \\
\hline The Netherlands & 52213 & 388 & 74.4 & 47247 & 83 & 17.6 \\
\hline Norway & 19652 & 146 & 74.3 & 17798 & 27 & 15.2 \\
\hline Sweden & 41928 & 315 & 75.1 & 39262 & 72 & 18.3 \\
\hline Switzerland & 30877 & 271 & 87.8 & 25808 & 59 & 22.9 \\
\hline Australia & 42812 & 524 & 122.5 & 40212 & 84 & 21.0 \\
\hline Belgium & 57847 & 300 & 51.8 & 50438 & 51 & 10.1 \\
\hline Canada & 60070 & 1080 & 179.8 & 61456 & 244 & 39.7 \\
\hline Denmark & 24465 & 160 & 65.4 & 22076 & 31 & 14.0 \\
\hline Finland & 21965 & 90 & 41.0 & 16671 & 28 & 16.8 \\
\hline Poland & 122695 & 336 & 27.4 & 97732 & 76 & 7.8 \\
\hline Russia & 470626 & 1605 & 34.1 & 235003 & 201 & 8.5 \\
\hline UK & 318869 & 2438 & 76.5 & 270280 & 288 & 10.6 \\
\hline USA & 780115 & 12706 & 162.9 & 728821 & 2253 & 30.9 \\
\hline
\end{tabular}

Source: Human Mortality Database (stock data) and national census data available through national statistical institutes for Sardinia and Okinawa.

100. Even if the specificity of the selected cohort may limit the comparative power of the CR, its advantage is that the data required for its computation are easily available from population censuses as well as in the Human Mortality database. Still, the interpretation of $\mathrm{CR}$ values relies on the assumption that the net international migration between ages 60 and 100 years can be neglected for the considered cohort.

Using the data from the Human Mortality database for observed countries, and data provided by the national data sources for Sardinia and Okinawa, we calculated the CR for the cohort born in 1900. For that specific cohort the observed number of persons aged 100 on 31 December 2000 was compared with the observed number of persons aged 60 in the same population on 31 December 1960, that is forty years earlier. The figures presented in Table 1 support the idea that males in Okinawa and Sardinia have a higher longevity compared to their peers in other countries. Extremely high values were observed for women in Okinawa, being three times higher than for women in all of Japan.

Although the CR can be used with some limitations to compare longevity at national level, it is less appropriate for smaller populations because of the limited number of persons reaching age 100 within a cohort corresponding to a single year 
of birth (among the BZs, only Okinawa has a sufficient number of centenarians to compute the CR). Accordingly, it is preferable to consider the between-census survival of broader population groups by comparing, for example, the number of persons aged 60-69 years in a 1970 census with those recorded thirty years later in a 2000 census and aged 90-99 or, alternatively, comparing the number of 60-79 years olds in 1970 and the aged 90+ thirty years later. In Table 2 these alternative CR are presented for the four longevity BZs as well as a few other countries. When interpreting these figures the possible bias resulting from migration should be kept in mind. In cases where the net migration cannot be neglected, these figures are automatically over-estimated if the population experienced a positive net migration during the 30 years' period before observation, or under-estimated in case of negative net migration. The figures in Table 2 display the superiority of Okinawa for women and of Sardinia for men. As for Ikaria, owing to high rates of emigration of old persons to the Athens Metropolitan Area, their figures are under-estimated. By contrast, for Costa Rica and Nicoya, important immigration from abroad and age exaggeration among nonagenarians in the 2000 census (Roxero-Bixby 2008) cause an inflation of CR.

The table in Appendix 1 shows summary ecological and socio-economic variables, selected from the existing literature, for the four BZs known so far, taking into account their possible role as longevity determinants. Most geographical features, though somewhat variable across the four sites, point predominantly to a condition of insularity and remoteness. The site altitude ranges from sea level to mid-mountain, with the highest value being found in the Sardinia BZ and the lowest in the Okinawa BZ. Average steepness of land, which correlates with altitude, reaches a maximum in the two Mediterranean islands and a minimum in Okinawa. The climate varies greatly across the four sites with a prevalence of relatively warm temperatures. A noteworthy observation, even when taking into account the large geographic heterogeneity of the four sites, is that high levels of sunlight, wind speed and humidity seem to be prevalent. Some socio-economic factors observed in the BZs, especially the lower degree of industrialisation and income per capita, seem to indicate the presence of populations emerging from a long-standing state of economic vulnerability although they may have experienced a constant improvement of their well-being level during the last few decades. Besides, some lifestyle and health indicators such as the moderate average calorie intake and the low prevalence of overweight/obesity in the adult population indicate a strong persistence of traditional habits, along with a low susceptibility to adopt a more Western lifestyle.

\section{Discussion}

The concept of BZ aims at characterising an area where a population sharing a common lifestyle and environment displays exceptionally high longevity. The first question to discuss is the very existence of such areas and whether the methods used to demonstrate their high level of longevity and compare longevity between 
Table 2:

Probability to survive between 1970 and 2000 for the 1890-1919 birth cohorts

\begin{tabular}{|c|c|c|c|c|c|c|}
\hline & \multicolumn{2}{|c|}{ Persons in 1970} & \multicolumn{2}{|c|}{ Persons in 2000} & \multicolumn{2}{|c|}{$\begin{array}{c}\text { Survival rates }(\%) \\
1970-2000^{(1)}\end{array}$} \\
\hline & Age 60-69 & Age 60-79 & Age 90-99 & Age 90+ & $90-99 / 60-69$ & $90+/ 60-79$ \\
\hline \multicolumn{7}{|l|}{ Males } \\
\hline Italy & 2311202 & 3384724 & 84276 & 85131 & 3.1 & 2.0 \\
\hline Sardinia & 58178 & 87965 & 3369 & 3422 & 5.8 & 3.9 \\
\hline Villagrande & 172 & 259 & 23 & 23 & $13.4^{* * *}$ & $8.9^{* *}$ \\
\hline Japan & 3098290 & 4544841 & 159302 & 161297 & 5.1 & 3.5 \\
\hline Okinawa & 19685 & 30592 & 1978 & 2031 & $10.0^{* * *}$ & $6.6^{* * *}$ \\
\hline Costa Rica & 27605 & 39590 & 3050 & 3154 & 11.0 & 8.0 \\
\hline Nicoya & 1700 & 2347 & 211 & 221 & 12.4 & $9.4^{*}$ \\
\hline Greece & 379960 & 561124 & 8846 & 9386 & 2.3 & 1.7 \\
\hline Ikaria & 604 & 800 & 20 & 20 & 3.3 & 2.5 \\
\hline France & 2259802 & 3352607 & 90236 & 91159 & 4.0 & 2.7 \\
\hline USA & 7117859 & 11011845 & 312843 & 318473 & 4.4 & 2.9 \\
\hline \multicolumn{7}{|l|}{ Females } \\
\hline Italy & 2697844 & 4292653 & 257827 & 262360 & 9.6 & 6.1 \\
\hline Sardinia & 61377 & 98411 & 6446 & 6580 & 10.5 & 6.7 \\
\hline Villagrande & 166 & 269 & 22 & 23 & 13.3 & 8.6 \\
\hline Japan & 3467619 & 4514236 & 464402 & 473879 & 13.4 & 10.5 \\
\hline Okinawa & 28258 & 46237 & 7226 & 7544 & $25.6^{* * *}$ & $16.3^{* * *}$ \\
\hline Costa Rica & 27456 & 39930 & 4150 & 4282 & 15.1 & 10.7 \\
\hline Nicoya & 1518 & 2179 & 225 & 245 & 14.8 & 11.2 \\
\hline Greece & 417664 & 657288 & 26203 & 27379 & 6.3 & 4.2 \\
\hline Ikaria & 532 & 856 & 47 & 49 & $8.8^{*}$ & $5.7^{*}$ \\
\hline France & 2720096 & 4599804 & 318095 & 325260 & 11.7 & 7.1 \\
\hline USA & 8407784 & 13815593 & 1025834 & 1060367 & 12.2 & 7.7 \\
\hline
\end{tabular}

Source: Data source: Human Mortality Database (stock data) and national census data available through national statistical institutes for Sardinia and Okinawa.

(1) The survival rates for Villagrande, Okinawa, Nicoya and Ikaria have been compared with the corresponding ones for Sardinia, Japan, Costa Rica and Greece, respectively. The statistical Z-test for two proportions shows significant differences at $5 \%\left({ }^{*}\right), 1 \%\left({ }^{* *}\right)$ or $0.1 \%\left({ }^{* * *}\right)$.

different populations are adequate. The second question is whether some ecological characteristics of the four BZs could be considered as potential determinants of the exceptional longevity of such populations. However, before discussing these two questions it is worth reminding that the age of a person is measured by the number of chronological years from birth. Therefore, validating accurately the age of every centenarian and ensuring the exhaustiveness of collected data is an absolute prerequisite for assessing and comparing the levels of population longevity. Inaccuracy in extreme ages has been often reported in the past and is still commonly 
found today in populations lacking civil registration (Kannisto 1988; Wilmoth and Lundstrom 1996; Poulain 2010). By the available evidence, data sources differ considerably between the four BZs, with the most favourable situation in Sardinia and the weakest one in Ikaria. Nevertheless, based on research done by other scientists as well as on our own investigations we are confident that the high level of longevity of these populations is real even if more in-depth validation could still be helpful to confirm our findings.

Among several indicators, which one should be considered ideal to compare longevity between different populations? We would briefly like to summarise the pros and cons of two indicators, i.e. CR and ELI.

- CR estimates the survival of cohort(s) between two different censuses. It can be computed by using census data or the Human Mortality Database under the hypothesis of the net international migration being negligible. Unfortunately, CR cannot be used to compare longevity at local level as cohorts may be too small and in a large number of cases no centenarians are found at the second census in many municipalities. Moreover, the assumption of negligible net migration, while possibly acceptable at national level, is no longer valid at local level where a significant number of old people may move away to another municipality, either to a nursing home or the residence of one of their children. Thus, CR cannot be used to compare the longevity between sizable long-living populations.

- ELI was used at local level in Sardinia because it was possible to match every birth with the corresponding death by using the marginal annotations in the birth register. This information allows identifying every death at age 100 and over, regardless of where it has occurred. Moreover, to overcome the problem of small number of newborns the data of all Sardinian cohorts from 1881 to 1901 included have been pooled. Unfortunately ELI cannot be computed in the three other BZs as birth registers are either lacking (Ikaria) or inaccessible (Okinawa) or no marginal annotations on death exist for every newborn (Nicoya).

Having in mind these limitations the data gathered in Table 2 confirm the exceptional longevity in Okinawa for both men and women compared to all of Japan while similar levels of longevity are also found in the Sardinian BZ compared to Sardinia as a whole, but for men only. Also women in Ikaria are shown to live longer than Greek women in general, which cannot be confirmed for men. Due to migration biases it has not been possible to prove any exceptional level of longevity in the Nicoya $\mathrm{BZ}$ and more details on the longevity registered in that population are proposed by Roxero-Bixby (2013) in this volume.

As far as the second point of the discussion is concerned, the comparison of the four BZs relies on the underlying assumption that, despite the large number of potential causes involved in the increased survival at individual level, a more limited subset of 'shared longevity determinants' may exist at population level. The utility of the BZ concept can be easily appreciated as these populations exhibit an unusual level of homogeneity in both environment and lifestyle. Moreover the comparison of the 
four BZs favours replication studies as well as testing of hypotheses across various ethnic and cultural settings. The comparison proposed here for the first time is rather limited, qualitative in essence, and takes into consideration only a few ecological and socio-cultural variables as potential predictors of longevity, selected on the basis of the available evidence and sparse literature data. Nevertheless some interesting features could emerge that will be the starting point for additional investigations.

Among the ecological variables, geographical features such as altitude and terrain steepness are particularly intriguing. Most populations who enjoy high life expectancy have been reported to live in mountains. Although many of them turned out to be myths (Leaf 1981) it has been suggested that living at high altitude could reduce the risk of mortality especially from cardiovascular disease. While this could be true for truly high elevations (above 1500 meters), it is rather questionable for lower altitudes. Besides, a recent study across US counties reported that after adjustment for confounding variables the association between altitude and life expectancy is no longer significant (Ezzati et al. 2012). Nevertheless, it is possible that people living even at modest elevation might benefit from positive effects on their health that could be partly explained by the relative isolation of these areas. As matter of fact, life in the mountains or on a remote island is associated with a set of tightly linked variables affecting both individual behaviour (diet, physical activity) and, more generally, the social context (habitat, economic activity, community support) and the environment (degree of pollution, quality of drinking water). All these factors are regarded as having a positive influence on health. Mountain environment is associated with increased land steepness which entails a constant stimulus for outdoor physical activity even by subjects in advanced age. Recently we have suggested that the elevated average slope of the terrain, fairly common in mountainous areas, may imply greater energy expenditure during active life, thus resulting in improved cardiorespiratory fitness, and ultimately in better survival (Pes et al. 2011).

In the past, populations living in mountains were likely to suffer from a degree of isolation that led to delayed economic growth compared to the whole country. During the early stages of industrialisation in Western countries, mountain areas were often regarded as backward pockets where traditional agro-pastoral activities persisted despite the rise of industrialism. However, this had important individual and social consequences, including a better preservation of the traditional habitat and a lower probability of coming into contact with health-threatening pollutants, not to mention a more satisfying and less alienated individual and occupational life. This, perhaps unintentionally, allowed a relevant proportion of the population to maintain the traditional way of life centred on tight social relationships, meaningful emotional exchange between generations and a considerable degree of support for weaker individuals by the community as a whole that in the long run could have been beneficial for survival.

The observation that all the BZs identified so far are slightly economically underdeveloped compared to the rest of their respective country, as reflected by their lower per capita income, seems to defy the so-called social gradient theory postulated by Evans (1994) stating that longevity would increase in proportion with 
the economic prosperity owing to its advantages in reducing anxiety and stress. When looking at the regional level, as highlighted by Cockerham (2000) in the case of Okinawa, areas ranking higher on levels of health are those where the process of modernisation came later and more slowly, as in the case of the three other BZs. This apparent discrepancy linking low income with longevity can be better understood if the economic development of these areas is evaluated in relative rather than absolute terms. When around the middle of the last century areas like Sardinia and Ikaria started their economic development, largely assisted by their governments, this resulted mainly in shifting from extreme poverty and deprivation to a relative material well-being, with limited social stratification. As pointed out by Poland (1998), the absence of a true class gradient and a consequent absence of social competition and individual stress, hallmarks of the Sardinian and Greek BZs, might have created significantly more favourable conditions for individual health than those operating in the more competitive mainland framework, a hypothesis that should be checked also for Okinawa and Nicoya.

Other life-shortening factors listed in Appendix A.1, such as smoking habits, the obesity rate and suicide prevalence, display a wide variation across the various BZs and their value is surprisingly high in some of them. This, however, does not provide evidence of their lack of influence on survival if we take into account two particular aspects: (i) the variable values might refer to the current population and do not necessarily reflect the historical situation of previous generations; (ii) the influence of potentially negative factors might be counteracted by concomitant factors acting in the opposite direction. The latter seems to be the cause of the paradox reported in some long-lived populations whose lifestyle appears to be unhealthy (Rajpathak 2011) yet it is buffered by coexisting protective factors. In this regard some dietary factors also deserve attention. The average caloric intake of the BZ's populations, with the possible exception of Okinawa, is not distinct from the general population of their mainland countries and does not fit the criteria for calorie restriction with optimum nutrition considered up to now the only longevity-promoting diet (Fontana 2010). Of course it is theoretically possible that not the quantity itself but rather the quality of food might have played an important role in maintaining a high standard of health in these populations, an aspect that will deserve further research.

In conclusion, the BZs, representing the extreme manifestation of population ageing operating in many contemporary populations as well, should be potentially regarded as a promising theoretical model, perhaps as important as the model of centenarians in the field of individual longevity. In fact, these rare populations to some extent might have retained significant longevity-related cause-effect links that in other post-industrial populations are masked by the effect of greater heterogeneity in genetic, socio-economic and lifestyle aspects. 


\section{Future scientific research and policy implications}

The search for common longevity determinants in the different BZs is just beginning. Quantitative and qualitative surveys are currently under development in a comparative way for Sardinia and Ikaria, involving biomedical and behavioural aspects. A comprehensive approach is being considered, favouring the analysis of individual life as well as an anthropological viewpoint in order to understand how the various transitions experienced by the local community (fertility, epidemiology, education, communication, nutrition...) could have interacted to result in exceptional longevity. Additionally, blood samples are being collected to carry out some genetic and epigenetic investigations. In particular the study of DNA methylation is expected to be more useful in populations historically or geographically isolated such as the BZs, which were exposed to high levels of endogamy and have therefore progressively developed a significant reduction in their genetic diversity.

As far as policy implications are concerned, Appel (2008) expressed the thought that "Blue Zones, now limited to just a few populations in the world, can become commonplace". The question is how the lessons obtained from the BZs can be transposed for improving the healthy ageing of our post-industrial societies. This led Dan Buettner to initiate the Blue Zones Community Project, aimed at creating a programme at community level to help communities harness schools, businesses, families and governments into improving their residents' health and well-being.

The Blue Zones Project initiative to become a Blue Zones Community is a systems approach that allows citizens, schools, employers, restaurants, grocery stores and community leaders to work together on policies and programmes that will make the most impact and move the community towards optimal health and well-being. Blue Zones Project initiatives have been launched in several places in the US: Albert Lea in Minnesota, three beach cities near Los Angeles in California and, more recently, ten communities in Iowa. Specific lifestyle and environmental characteristics in each of the BZs are transposed to help American cities joining the project to optimise their own communities for better fitness and longevity.

For all Iowa communities, tools will be available to help them continue their path to improved wellbeing. The Blue Zones Project provides leadership training and guidance to help leaders transform their community, work and home environments. Can good-health practices of the world's longest-lived communities be transplanted into small US Midwestern cities? This is the real challenge. First results show how "the Blue Zones impact in how people eat and exercise, how they find new ways to build community and get to know each other, how they are cutting back areas for smoking and expanding opportunities for altruism - all key elements in creating a Blue Zones community" (Wolfe 2012). Nevertheless it is too early to assess the improvement in healthy ageing that could be associated with the implementation of the Blue Zone Community Project. Scientists should be attentive in the forthcoming years to develop accurate indicators that could help assessing the efficiency of such policy support initiatives. 


\section{Acknowledgements}

Support from the Estonian Ministry of Education and Science (SF1300018s11) and the Estonian Science Foundation grant No. 8325 for Michel Poulain and Anne Herm is gratefully acknowledged.

\section{Appendix}

\section{Table A.1:}

Ecological and socio-economic variables in the four BZ sites

\begin{tabular}{|c|c|c|c|c|}
\hline & Okinawa BZ & Sardinia BZ & Ikaria BZ & Nicoya BZ \\
\hline \multicolumn{5}{|l|}{ Geographic features } \\
\hline Area $\left(\mathrm{km}^{2}\right)$ & $1201^{\mathrm{a}}$ & $1559^{\mathrm{b}}$ & $255^{\mathrm{c}}$ & $778^{\mathrm{d}}$ \\
\hline Population & $1384762^{\mathrm{a}}$ & $42113^{\mathrm{b}}$ & $8312^{\mathrm{c}}$ & $326953^{d}$ \\
\hline Density (inhab./sq km) & 1015 & 27 & 31 & 67 \\
\hline Average latitude & $26^{\circ} \mathrm{N}$ & $39^{\circ} \mathrm{N}$ & $37^{\circ} \mathrm{N}$ & $10^{\circ} \mathrm{N}$ \\
\hline Site altitude & Sea level & Mid-mountain & Mid-mountain & Hills \\
\hline Average land steepness & Low & High & High & Medium \\
\hline Proximity to the sea & Yes & Yes & Yes & Yes \\
\hline \multicolumn{5}{|l|}{ Climate } \\
\hline Climate & Subtropical & Mediterranean & Mediterranean & Tropical \\
\hline Average annual temp and range $\left({ }^{\circ} \mathrm{C}\right)$ & $22.4(16-27)^{\mathrm{e}}$ & $16.9(16-18)^{\mathrm{f}}$ & $18.9(16-22)^{\mathrm{g}}$ & $26.4(23-28)^{\mathrm{h}}$ \\
\hline Average annual rainfalls (mm) & $\sim 2000^{\mathrm{e}}$ & $\sim 800^{\mathrm{i}}$ & $631^{\mathrm{j}}$ & $2178^{\mathrm{h}}$ \\
\hline Relative humidity $(\%)$ & $71^{\mathrm{e}}$ & $65^{\mathrm{i}}$ & $66^{\mathrm{g}}$ & $81^{\mathrm{h}}$ \\
\hline \multicolumn{5}{|l|}{ Land characteristics } \\
\hline Main geologic features & $\begin{array}{c}\text { Coralline } \\
\text { limestone, } \\
\text { volcanic rocks }\end{array}$ & $\begin{array}{l}\text { Granite and } \\
\text { basalt rocks }\end{array}$ & Granite rocks & $\begin{array}{c}\text { Sedimentary } \\
\text { rocks } \\
\text { (limestone) }\end{array}$ \\
\hline Background radioactivity & Low & High & High & Low \\
\hline Drinking water hardness & $\operatorname{High}^{\mathrm{k}}$ & Low ${ }^{1}$ & Low $^{\mathrm{m}}$ & $\operatorname{High}^{\mathrm{n}}$ \\
\hline Forest coverage $(\%)$ & $46^{\circ}$ & $83.1^{\mathrm{p}}$ & $>80^{\mathrm{j}}$ & $3^{q}$ \\
\hline \multicolumn{5}{|l|}{ Socio-economic indexes } \\
\hline Local income (LI) per capita & $\sim \$ 21000^{\mathrm{r}}$ & $\$ 19872^{\mathrm{s}}$ & $\$ 26235^{\mathrm{t}}$ & $\$ 8700^{\mathrm{u}}$ \\
\hline Agriculture (\% of LI) & 1.9 & 1.4 & 12.2 & 18.2 \\
\hline Manufacturing (\% of LI) & 4.7 & 16.8 & 9.7 & 7.7 \\
\hline Services $(\%$ of LI) & 89.5 & 81.8 & 78.1 & 64 \\
\hline Vehicles per 1,000 inhabitants & $490^{r}$ & $360^{\mathrm{b}}$ & $200^{t}$ & $177^{\mathrm{u}}$ \\
\hline \multicolumn{5}{|l|}{ Lifestyle and health indicators } \\
\hline Daily food intake per capita (kcal) & $<2000^{\mathrm{k}}$ & $2600^{v}$ & $<1500^{\mathrm{w}}$ & $2392^{x}$ \\
\hline Smoking rate $(\%)$ & $4.6^{\mathrm{y}}$ & $\sim 20^{\mathrm{z}}$ & $82(\operatorname{men})^{\mathrm{W}}$ & $40.3^{\mathrm{x}}$ \\
\hline Obesity rate (\%, BMI above 30$)$ & $10-40^{y}$ & $8.7^{\mathrm{aa}}$ & $12.5^{\mathrm{w}}$ & $23.6^{\mathrm{bb}}$ \\
\hline \multirow[t]{2}{*}{ Suicide rate (cases/100,000) } & $32.1 / 33.5(\mathrm{men})^{\mathrm{cc}}$ & $15.3^{\mathrm{dd}}$ & $2.35^{\mathrm{ee}}$ & $7.3^{\mathrm{ff}}$ \\
\hline & 9.1/14.6 (women) & & & \\
\hline
\end{tabular}




\section{Sources of data presented in Appendix 1}

a. http://en.wikipedia.org/wiki/Okinawa_Island

b. Poulain, M., G.M. Pes, C. Grasland, C. Carru, L. Ferrucci, G. Baggio, C. Franceschi, L. Deiana 2004. Identification of a geographic area characterised by extreme longevity in the Sardinia island: the AKEA study. Experimental Gerontology 39 (9): 1423-1429.

c. http://en.wikipedia.org/wiki/Icaria

d. Relative to the entire province of Guanacaste;

e. Ikema, T., G.R. Bigg, and R.G. Bryant (2010). Increasing rain intensity over Okinawa, 1982-2005, and the link to changes in characteristics of northwest Pacific typhoons. Journal of Geophysical Research, 115 (D24), doi: 10.1029/2010JD014428.

f. ISTAT (http://www3.istat.it/)

g. Karavitis, C.A. et al. 2012. "Assessing alternative water resources management scenarios in islands of the Aegean archipelago, Greece". Global NEST Journal, 14(3), 264-275.

h. Campos, O., E. Rodriguez and L. Ugalde 1992. Desarrollo Agropecuario Sostenible en la Region de Hojancha, Guanacaste, Costa Rica. Rep. No. 195, CATIE/ROCAP, Turrialba, Costa Rica.

i. Chessa, P. and A. Delitala 1997. Il Clima della Sardegna. SAR, Sassari, Italy.

j. Gouvas, M., and N. Sakellariou 2011. Climate and forest vegetation in Greece. National Observatory of Athens, Institute for Environmental Research and Sustainable Development. Library, Study No. 01/2011.

k. Willcox B.J., D.C. Willcox, H. Todoriki, A. Fujiyoshi, K. Yano, Q. He, J.D. Curb and M. Suzuki 2007. Caloric restriction, the traditional Okinawan diet, and healthy ageing. The diet of the world's longest-lived people and its potential impact on morbidity and life span. Annals of the New York Academy of Sciences, 1114: 434-455.

1. Angelillo, B. and U. Alamanni 1964. Sull'andamento nella provincia di Sassari della mortalità per malattie cardiocircolatorie in rapporto anche ad alcuni fattori alimentari. Igiene e Sanità Pubblica, 20: 429-435.

m. Lambrakis, N. and G. Kallergis 2005. Contribution to the study of Greek thermal springs: hydrogeological and hydrochemical characteristics and origin of thermal waters. Hydrogeology Journal, 13: 506-521.

n. Mora-Alvarado, D., N. Alfaro-Herrera, C. Felipe-Portuquez and M. PeinadorBrolatto 2000. Cálculos en las vías urinarias y su relación con el consumo de calcio en el agua de bebida en Costa Rica. Revista Costarricense de Salud Pública 9(17).

o. Li, Q., M. Kobayashi and T. Kawada 2008. Relationships Between Percentage of Forest Coverage and Standardised Mortality Ratios (SMR) of Cancers in all Prefectures in Japan. The Open Public Health Journal 1: 1-7.

p. Piano Faunistico Venatorio Provinciale 2011-2015. Provincia dell'Ogliastra, Assessorato all' ambiente. 
q. Sanchez-Azofeifa, G.A. 2001. Deforestation in Costa Rica: A Quantitative Analysis Using Remote Sensing Imagery. Biotropica 33: 378-384

r. Lopez-Rodriguez, J., and D. Nakamura 2011. Mind the Remoteness! Income disparities across Japanese Prefectures. Estudios de Economia 38: 393-417.

s. ISTAT, Distribuzione del reddito e condizioni di vita in Italia (2005-2006).

t. Eurostat 2008. Regional gross domestic product (PPS per inhabitant), by NUTS 2 regions.

u. Encuesta de Hogares (2001-2008) del Instituto Nacional de Estadísticas y Censos (INEC).

v. Tivaroni, J. 1928. "Nutrition patterns in Sardinia population". Rivista di Politica Economica, 2:1-11.

w. Panagiotakos, D.B., C. Chrysohoou, G. Siasos, K. Zisimos, J. Skoumas, C. Pitsavos and C. Stefanadis 2010. Sociodemographic and Lifestyle Statistics of Oldest Old People ( $>80$ Years) Living in Ikaria Island: The Ikaria Study. Cardiology Research and Practice, 2011 ID 679187, 7 pages, doi: 10.4061/2011/679187.

x. Kabagambe, E.K., A. Baylin, X. Siles and H. Campos 2002. Comparison of dietary intakes of micro- and macronutrients in rural, suburban and urban populations in Costa Rica. Public Health Nutrition, 5(6A): 835-42.

y. Willcox, D.C., B.J. Willcox, S. Yasura, M.A. Ashitomi and M. Suzuki 2012. Gender gap in healthspan and life expectancy in Okinawa: health behaviours. Asian journal of gerontology $\mathcal{E}$ geriatrics 7 : 49-58.

z. Indagine DOXA, Istituto Superiore di Sanità (ISS), 2011.

aa. Piras, I., M.E. Ghiani, A. Melis, S. Inghes, L. Salaris, A. Gatti, A. Loviselli, G. Vona and C.M. Calò 2006. Incidenza del sovrappeso e dell'obesità tra i coscritti sardi nati nel 1980. Antropo, 13: 35-43. www.didac.ehu.es/antropo

bb. Chen-Ku, C. H. and M.G. Sandí-Bogantes 2004. Actualización en obesidad. Acta Médica Costarricense 46, suppl. 1.

cc. Chen, J., Y. J. Choi, and Y. Sawada 2009. "How is Suicide Different in Japan?" Japan and the World Economy, 21(2): 140-50.

dd. Maggian, R. 2011. Guida al welfare italiano: dalla pianificazione sociale alla gestione dei servizi. Maggioli ed.

ee. Giotakos, O., G. Tsouvelas and V. Kontaxakis 2012. Suicide rates and mental health services in Greece. Psychiatriké 23(1): 29-38.

ff. Granados-Bloise, D. 1998. Magnitud y Tendencia del Suicidio en los Cantones de Costa Rica: 1980-1994. Revista Costarricense de Salud Pública 7: 23-35.

\section{References}

Appel, L. J. 2008. "Dietary Patterns and Longevity Expanding the Blue Zones". Circulation 118 (3): 214-215. doi:10.1161/CIRCULATIONAHA . 108.788497. 
Bowerman, W. G. 1939. "Centenarians". Transactions of the Actuarial Society of America 40: 361-378.

Buettner, D. 2010. The Blue Zones: Lessons for Living Longer From the People Who've Lived the Longest. Washington, D.C.: National Geographic.

Cockerham, W. C., H. Hattori, and Y. Yamori. 2000. "The Social Gradient in Life Expectancy: The Contrary Case of Okinawa in Japan”. Social Science $\mathcal{E}$ Medicine 51 (1): 115-122.

Deiana, L., L. Ferrucci, G. M. Pes, C. Carru, G. Delitala, A. Ganau, S. Mariotti, A. Nieddu, S. Pettinato, P. Putzu, C. Franceschi, and G. Baggio. 1999. "AKEntAnnos The Sardinia Study of Extreme Longevity". Aging, Clinical and Experimental Research 11 (3): 142-149.

Evans, R. G. 1994. "Why Are Some People Healthy and Others Not? Introduction." In The Determinants of the Health of Populations, ed. by R. G. Evans, M. L. Barer, and T. R. Marmor, 3-26. New York: Aldine de Gruyter.

Ezzati, M., M. E. M. Horwitz, D. S. K. Thomas, A. B. Friedman, R. Roach, T. Clark, C. J. L. Murray, and B. Honigman. 2012. "Altitude, Life Expectancy and Mortality From Ischaemic Heart Disease, Stroke, COPD and Cancers: National PopulationBased Analysis of US Counties". Journal of Epidemiology and Community Health 66 (7): e17. doi:10.1136/jech.2010.112938.

Fontana, L., L. Partridge, and V. D. Longo. 2010. "Extending Healthy Life Span From Yeast to Humans". Science 328 (5976): 321-326. doi:10.1126/science. 1172539.

Jeune, B., and J. W. Vaupel. 1999. "Species of Evidence of Exceptional Longevity". In Validation of Exceptional Longevity, ed. by B. Jeune and J. W. Vaupel, 11-22. Monographs on Population Aging 6. Odense: Odense University Press.

Kannisto, V. 1988. "On the Survival of Centenarians and the Span of Life". Population Studies 42 (3): 389-406. doi:10. 1080/0032472031000143546.

Koenig, R. 2001. "Sardinia's Mysterious Male Methuselahs". Science 291 (5511): 2074-2076. doi:10.1126/science.291.5511.2074.

Leaf, A. 1973. "Every Day Is a Gift When You Are Over 100". National Geographic 143 (1): 93-118.

Leaf, A. 1981. "Statement Regarding the Purported Longevous Peoples of Vilcabamba". In Controversial Issues in Gerontology, ed. by H. Hershow, 25-26. New York: Springer Publishing Company, Inc.

Mazess, R., and S. Forman. 1979. "Longevity and Age Exaggeration in Vilcabamba, Ecuador". Journal of Gerontology 34 (1): 94-98.

Perls, T. T., L. M. Kunkel, and A. A. Puca. 2002. "The Genetics of Exceptional Human Longevity”. Journal of the American Geriatrics Society 50 (2): 359-368. 
Pes, G. M., F. Tolu, M. Poulain, A. Errigo, S. Masala, A. Pietrobelli, N. C. Battistini, and M. Maioli. 2013. "Lifestyle and Nutrition Related to Male Longevity in Sardinia: An Ecological Study". Nutrition, Metabolism and Cardiovascular Diseases 23 (3): 212-219. doi:10.1016/j . numecd.2011.05 . 004.

Poland, B., D. Coburn, A. Robertson, and J. Eakin. 1998. "Wealth, Equity and Health Care: A Critique of a Population Health Perspective on the Determinants of Health". Social Science E Medicine 46 (7): 785-798.

Poulain, M. 2010. "On the Age Validation of Supercentenarians". In Supercentenarians, ed. by H. Maier, J. Gampe, B. Jeune, J.-M. Robine, and J. W. Vaupel, 3-30. Demographic Research Monographs 7. Springer Berlin Heidelberg.

Poulain, M. 2011. "Exceptional Longevity in Okinawa: A Plea for In-Depth Validation". Demographic Research 25 (7): 245-284. doi:10 . 4054 / DemRes . 2011.25.7.

Poulain, M., and G. M. Pes. 2009. Report on the Validation of the Exceptional Longevity in Ikaria. Unpublished Internal Report. National Geographic.

Poulain, M., G. M. Pes, C. Carru, L. Ferrucci, G. Baggio, C. Franceschi, and L. Deiana. 2006. "The Validation of Exceptional Male Longevity in Sardinia". In Human Longevity, Individual Life Duration, and the Growth of the Oldest-Old Population, ed. by J.-M. Robine, E. M. Crimmins, S. Horiuchi, and Z. Yi, 147-166. New York: Springer / Kluwer.

Poulain, M., G. M. Pes, C. Grasland, C. Carru, L. Ferrucci, G. Baggio, C. Franceschi, and L. Deiana. 2004. "Identification of a Geographic Area Characterized by Extreme Longevity in the Sardinia Island: The AKEA Study". Experimental Gerontology 39 (9): 1423-1429. doi:10.1016/j . exger . 2004 .06.016.

Rajpathak, S. N., Y. Liu, O. Ben-David, S. Reddy, G. Atzmon, J. Crandall, and N. Barzilai. 2011. "Lifestyle Factors of People With Exceptional Longevity". Journal of the American Geriatrics Society 59 (8): 1509-1512. doi:10.1111/j . 1532-5415.2011.03498.x.

Robine, J.-M., and G. Caselli. 2005. "An Unprecedented Increase in the Number of Centenarians”. Genus 61 (1): 57-82.

Rosero-Bixby, L. 2008. "The Exceptionally High Life Expectancy of Costa Rican Nonagenarians". Demography 45 (3): 673-691.

Rosero-Bixby, L., W. H. Dow, and D. H. Rehkopf. 2013. "The Nicoya Region of Costa Rica: A High Longevity Island for Elderly Males”. This volume, Vienna Yearbook of Population Research 11: 109-136.

Saito, Y. 2010. "Supercentenarians in Japan". In Demographic Research Monographs, ed. by H. Maier, J. Gampe, J. M. Robine, and J. W. Vaupel, 75-99. Rostock: Max Planck Institute. 
Willcox, D. C., B. J. Willcox, Q. He, N.-c. Wang, and M. Suzuki. 2008. "They Really Are That Old: A Validation Study of Centenarian Prevalence in Okinawa". The Journals of Gerontology. Series A: Biological Sciences and Medical Sciences 63 (4): 338-349.

Wilmoth, J. R., and H. Lundström. 1996. "Extreme Longevity in Five Countries: Presentation of Trends With Special Attention to Issues of Data Quality". European Journal of Population 12: 63-93. doi:10.1007/BF01797166.

Wolfe, W. 2012. "Blue Zone Offers Lessons in Longevity". Star Tribune.

Young, R. D., B. Desjardins, K. McLaughlin, M. Poulain, and T. T. Perls. 2010. “Typologies of Extreme Longevity Myths". Current Gerontology and Geriatrics Research 2010 (423087). doi:10.1155/2010/423087. 